\title{
Exploring the Nature of Continuing Professional Development (CPD) Programs in a Language Institute
}

\author{
Hussain Ahmad \\ English Language Institute, King Abdul-Aziz University \\ Jeddah 21589, PO Box 80200, Saudi Arabia \\ Sayyed Rashid Shah \\ English Language Institute, King Abdul-Aziz University \\ Jeddah 21589, PO Box 80200, Saudi Arabia \\ Emad A. Alghamdi \\ English Language Institute, King Abdul-Aziz University \\ Jeddah 21589, PO Box 80200, Saudi Arabia \\ Sayyed Rashid Shah (Corresponding author) \\ English Language Institute, King Abdul-Aziz University \\ Jeddah 21589, PO Box 80200, Saudi Arabia \\ E-mail:srshah@kau.edu.sa
}

Received: February 14, 2016 Accepted: February 29, 2016 Published: March 28, 2016

doi:10.5296/ire.v4i1.9022 URL: http://dx.doi.org/10.5296/ire.v4i1.9022

\begin{abstract}
When it is an undeniable reality that learning is at the centre of teaching profession, we assume that the continuing professional development would be a priority for all teachers. EFL teachers like the teachers of other subjects update their skills and knowledge base in order to keep abreast of the new developments and challenges in the field of English language
\end{abstract}


teaching. The present study seeks to explore how EFL teachers in an English language institute at a Saudi Arabian university perceive the effectiveness of Continuing Professional Development in their context as well as the ways in which different modes of CPD can promote and enhance the teachers' learning. This study was conducted at an English language institute of a Saudi university. The study adopted a quantitative approach using online questionnaire. The quantitative data was collected from $50 \mathrm{EFL}$ teachers who were qualified and experienced in the field of TESOL. The findings from the study showed that the teachers viewed external CPD such as courses, seminars, workshops and conferences, and self-directed endeavors like informal discussions, reading professional literature, and self-reflection more beneficial to their development than the internal C:PD like classroom observations and other in-house training sessions. This paper concludes that the institution should improve its internal professional development scheme by expanding the professional development unit's role, enhancing the quality of its mentoring program, and establishing communities of practice wherein teachers engage in highly professional practices.

Keywords: continuous professional development, EFL teachers, community of practice

\section{Introduction}

EFL teaching has undergone significant changes worldwide in order to meet the emerging needs of EFL students in coping with their educational and social demands. Globally there has been an increased emphasis on the development of EFL teachers to adapt their strategies and beliefs to keep at par with the ever-changing nature of a dynamic classroom. Adey (2004, p. 2) states that education system stagnates if it does not change, as pedagogical practices that worked 20 years ago may not work today. Therefore, for effective language teaching and learning, Continuing Professional Development (CPD) is a dynamic concept which outlines that teachers must change their teaching-learning practices to introduce a widespread change influencing learners' performance. CPD enables the EFL teachers to have different perspectives and gain insight into understanding their own performances as well as the positive and negative impact instructions might have on the students. Prosser and Trigwell (1997, p. 142) have also highlighted that teachers who focus on students and students' learning outcomes train the students in meaning and understanding, whereas teachers who focus on themselves lead the students focus on reproduction. Thus, CPD offers teachers an opportunity to reflect on their own practices and make their teaching student-centered to achieve maximum learning outcomes.

Like anywhere else, the Gulf teachers, particularly EFL practitioners in Saudi context face the challenge of shaping their teaching practices according to the international standards of ELT. Currently more than a dozen universities in the Kingdom of Saudi Arabia conduct teacher training programs at different colleges; however, according to Khan (2011, p. 119) the EFL teachers are disinterested in CPD programs in spite of the fact that institutions allocate a lot of funds for research and development. Mainly, these professional development activities are not considered effective due to their failure to provide context-specific training and meet the EFL teachers' professional development needs. Consequently, teachers lack awareness to understand the challenges faced by EFL learners and thus, the institutions fail to 
meet the international standards. Although EFL teachers in Saudi Arabia are qualified and experienced, Rahman and Al-haisoni (2013, p. 115) remark that having credentials or being qualified is a requirement for a job not a guarantee for a good teacher, thus, teachers in the Saudi context are often required to be cognizant of the cultural norms, students' interests, leadership practices and institutional policies which can be accounted as context-specific phenomena and can only be achieved in CPD courses that is in line with local and regional demands. As context-specific professional development activities are deemed vital to the effectiveness of EFL teaching and learning, this study aims to explore the effectiveness of CPD courses offered to EFL teachers in a Saudi university.

\section{Literature Review}

\subsection{Continuing Professional Development in General}

Globalization has its impact on educational organizations which aim to transform their practices and ensure high quality instructions at all levels. This glimpse of these transformational efforts can be seen in emphasis given to teacher training and professional development courses around the world. Though the significance of teacher training cannot be denied, literature indicates that "educational change depends on what teachers do and thinkit's as simple and as complex as that" (Fullan \& Stiegelbauer, 1991, p. 117). Thus, training courses should focus on how to change the teachers' existing practices and develop pedagogical skills to maximize their teaching outcomes.

Continuing Professional Development, in a broader sense, refers to the professional development of a person in his/her professional arena. More specifically, the in-service professional development is the growth of a teacher as a result of acquiring invaluable experience and evaluating his teaching systematically (Glatthorn, 1995). According to Villegas-Reimers (2003) CPD has two major types: first, formal learning opportunities such as, attending workshops, mentoring sessions and courses; second, informal experiential learning which include reading books and research articles, interacting with colleagues and informal group discussion in a community of practice. In addition to the above factors, peer-observation, self-observation and self-reflection can inform one's teaching and students' achievement. However, Richard (2005) observes that personal and individual reflection cannot lead to subject matter knowledge and pedagogical expertise. Therefore, professional development should not be limited to self-observation and mere reflection and should encompass training sessions in order for the teachers to gain familiarization with new trends in subject matter and critical examination of the classroom realities.

Although professional development can be fruitful irrespective of where and how it takes place, sound planning and in-depth investigation of a teacher's professional and personal needs are pre-requisites of any professional development endeavor. Fullan (2001) furthers the discussions by suggesting that successful implementation of professional development requires continuous encouragement and clarity of purpose and the implementation of newly gained knowledge. This can be in the light of the teachers' professional needs, considering contextual factors that might need to be taken into account in order to ensure the suitability and efficacy of such courses in a local context. 


\subsection{EFL Continuous Professional Development}

Like teachers of other disciplines, EFL teachers seek to quench their thirst for professional growth by indulging in continuous professional development through formal and informal experiences to meet the expectations of the organizations and learners in different social contexts. Mcdonald (2010) believes that the phenomenal popularity of English language around the world has given rise to many challenges in the field of EFL/ESL. Bearing in mind the inevitable social, political and institutional barriers, Zuheer (2013) suggests that it is imperative for ESL teachers to have the courage, abilities and skills of dealing with the emerging issues in the field. Following this train of thoughts, Magno (2009:1) recommends that EFL practitioners need to be effective in: knowing how language is acquired, embracing strong beliefs about learning of EFL, and improving attitudes towards the learning-teaching process. EFL teachers' focus should primarily be on: the mechanics of English language, awareness of how to teach English, and students' effective learning. Therefore, Byram and Phips (2005) assert that in academic and pedagogic dimensions, EFL teacher education should offer teachers opportunities for both cognitive and experiential learning to foster personal and professional development.

Undoubtedly, we exist in an era of great cultural diversity. This poses a challenge for EFL teachers to adapt themselves to the culture of the learners and at the same time exploit the EFL learners' culture for better learning. I believe that EFL practitioner should equip themselves with the cultural background of the learners through continuous professional development, as Bandura, Castro (2005) maintain that language teaching has a language side and a culture side wherein EFL teachers face greatest pedagogical challenges of integrating both to make a sense of interconnectedness.

\subsection{EFL CPD in the Middle East}

In the Middle East EFL CPD has gained tremendous momentum in the recent years. Both institutional and external PD events have led to teachers' awareness in the realms of content knowledge and pedagogical expertise. For instance, in the UAE, according to Raza (2010) the institutional forms of CPD include communities of practices, workshops, online groups and seminars. Whereas for the external CPD teachers participate and contribute in TESOL Arabia, British Council programs, IATEFL and online discussion groups. Similarly, in Oman (Hayes, 2014) teachers of English are expected and encouraged to take part in self-directed CPD activities to remain professionally sound and in-touch with their professional growth in their entire career by taking part in professional courses such as British council's TKT. However, there is not sufficient capacity to fully realize the needs and aspirations of the EFL teachers. Moreover, in Yemen English teachers get pre-service and in-service training courses which are conducted by local administration. According to Alsofi (2009) although teachers are recruited by the Ministry of Education for different state-run schools and universities, the teachers of English language are not adequately trained to teach communicative syllabi due to limited exposure to PD avenues and as a result, therefore teaching next year is rarely different than the last year. 


\subsection{EFL CPD in Saudi Arabia}

In Saudi Arabia English language enjoys a prominent position in all walks of life from education to economy. The influx of foreign workers and exposure of Saudis to the Western cultures especially to English speaking nations has resulted in a positively attitude towards English language. Another somewhat recent drive on the part of the government to empower Saudi youth for sustainable development and to synchronize them with the market needs and competency has brought English language learning to the forefront among other required skills. At universities, students take English courses as a compulsory subject.

Regardless of the colossal importance of English language in Saudi Arabia, as maintained by Al-Seghayer (2014), Saudi EFL teachers are not competent enough to train their students properly. He (ibid) further says that the proficiency level of the majority of EFL teachers in Saudi Arabia is not up-to the mark to an extent that they are able to grasp the classroom realities. Therefore, various institutions are conscious of the debilitating conditions of EFL teachers and are serious in providing them with professional development opportunities across the kingdom. It is due to this raised consciousness some institutions have made the acquisition of teaching certification imperative for EFL teachers causing a domino effect of the introduction of CELTA course by the British Council in some major cities here in the Kingdom. Moreover, KSAALT (The Kingdom of Saudi Arabia Association of Language Teachers) provides English language teachers with opportunities in promoting and supporting language instructions and teaching methodologies. KSAALT also hosts different workshops and seminars and publish research journal to fulfill the emerging needs of the EFL/ESL teachers from different institutions in the Kingdom.

Khan (2011) holds the view that there are three categories of English teachers in Saudi Arabia: Native speakers, bilinguals (Arabs) and teachers from Pakistan and India. Most of these teachers face problems in teaching English in the Kingdom. For instance, the native speakers have done only short courses like CELTA but have no post-graduate level qualifications in teaching. Although the bilingual Arabs and Pakistani and Indians are qualified, they also fail to grasp the classroom realities.

In the same way, Al-Harbi (2006) noted that Saudi EFL teachers in Al-Qasim province are deemed incompetent for imparting English language knowledge. Likewise, AlShaifan (2009) investigated the professional development of EFL teachers in Saudi Arabia and arrived at the conclusion that EFL teacher preparation programs lack content knowledge such as linguistics and pedagogical knowledge like course designing and cultural sensitivity. Along the same line, Zohairy (2012) explored the current trends in continuous professional development of EFL teachers in seven government universities and four private universities. He concluded that only two universities conduct EFL teacher training programs; however, the teachers showed discontent of these programs. The call for improvement of EFL teacher preparation programs was also echoed by several other researchers (Zafer, 2002; AlHazmi, 2003; Al-Seghayer, 2005).

In Saudi EFL context, Shah, Hussain and Nasseef (2013) explored the challenges of EFL teachers that could potentially impact their classroom practices. They concluded that EFL 
teaching was influenced by three major factors: a) Social, cultural, and religious sensitivities; b) Lack of learners' motivation; and c) Unfavorable institutional policies and procedures. However, the EFL teachers were able to offset those challenges with their 'keen awareness of Saudi culture, thorough understanding of the learners' needs, and professional competence, the unfavorable effects of these factors might be neutralized or minimized' (Shah et al., 2013: 104). As the literature review highlights the significance of CPD in various contexts around the world, it can be equally considered important in the Saudi EFL context. Thus, the research aims to answer the following research question:

Research Question: How do EFL teachers perceive the effectiveness of Continuous Professional Development (CPD) programs in the Saudi EFL context?

\section{Method of Data Collection}

This study adopts a quantitative methodology to collect data as Liebscher (1998) argues that quantitative method can be easily validated. Additionally, as this study focuses on teachers' behavior, attitudes and performance in the domain of CPD, quantitative methodology yields better and more accurate results in similar scenarios.

For data collection, a closed-ended survey questionnaire comprising 30 statements was used. The questionnaire was sent out to the EFL teachers across the institution. For the questions, choices comparable to the Likert-scale were employed (Trochim, 2006) which ranged from Strongly Agree, Agree, Neutral, Disagree and Strongly Disagree. The reason behind choosing a questionnaire was to reach out to most of the selected teachers in a limited period of time. Also, information obtained through a survey questionnaire, according to Open University Team (2001), represents a large group and is more reliable. Moreover, to make the questionnaire easily understandable and respondent-friendly, a pilot questionnaire was administered to make sure the appropriateness of the data collection, as Cohen, Manion \& Morrison (2007) believe unsophistication and flexibility of a questionnaire guarantee more and true responses. Finally, a variety of choices were presented in the questionnaire in order to encourage the respondents to do this work by involving their desire for self-expression, interpersonal response, intellectual challenge, self-understanding, altruism, or emotional catharsis (Wawrick \& Lininger (1975:185). To this end, all aspects and motives of continuous professional development were reviewed and teachers were encouraged to indulge in soul-searching experience of their professional odyssey.

Besides the appropriateness and suitability of the questions, the respondents were not coerced into completing the questionnaire, rather were given the freedom to withdraw from the survey whenever they wanted, as the participants "are subjects not objects of research" (Cohen et al., 2007:318).

The participants were from the English Language Institute of Saudi university who were well aware of the purpose of the questionnaire and were formally informed that their answers would be dealt with anonymously. All of them were male due to the fact that in KSA gender segregation is practiced in all walks of life including educational institutions. They were all experienced and qualified teachers in EFL/ESL. The participants had a minimum five years 


\section{Macrothink}

of teaching experience in the Saudi EFL context. They were native English speakers, bilingual Arabic speakers and Pakistanis and Indians. A random sampling strategy was adopted to choose informants from the aforementioned communal groups for the current project in order for the project's results to represent the views of all three major groups. As Lodico, Spaulding \& Voegtle (2010) maintain that random selection ensures equal representation of all members of a large group; in this study all members from all different ethnic or linguistic communities were given a chance to share their views on CPD in the same institute. Out of 250 plus teachers only 50 teachers took part in the project survey which was sent out to them electronically.

\section{Results}

This section presents the findings of a small-scale empirical study. The survey questionnaire was consisted of thirty statements which were summarized and categorized in the following eight broader categories.

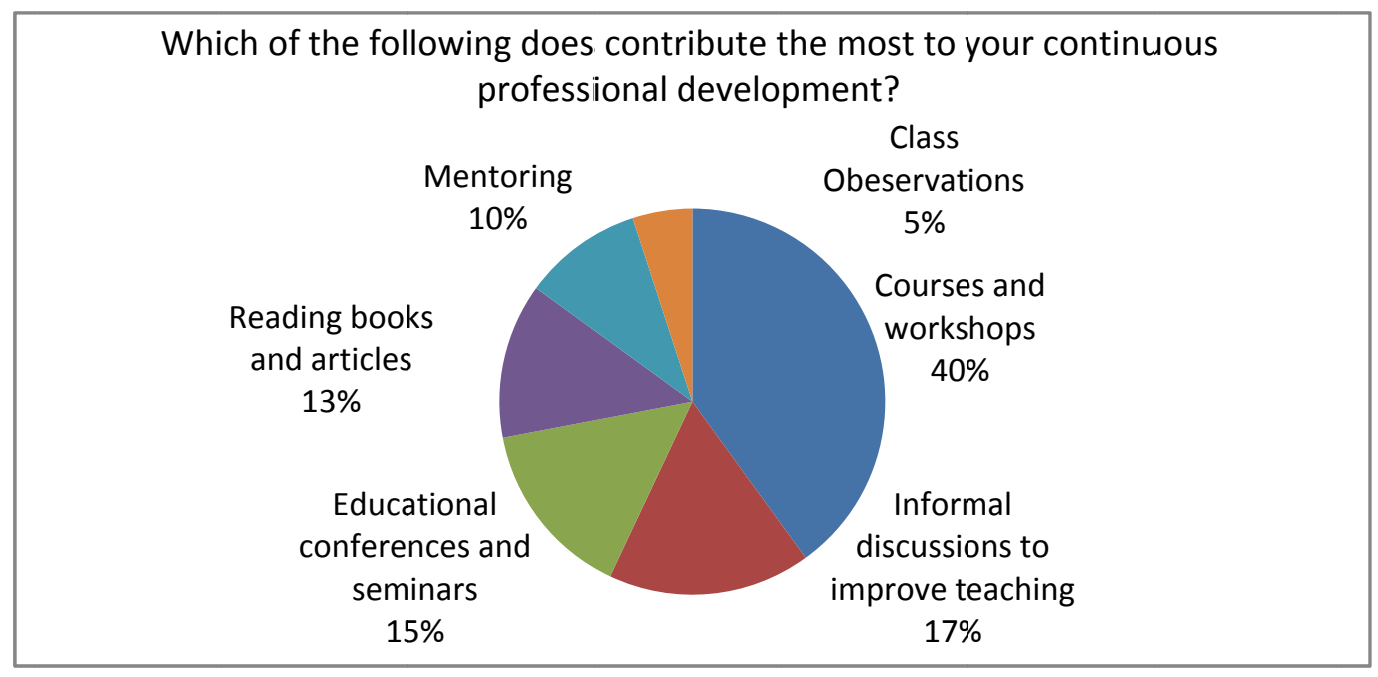

Figure 1. Factors contributing to the professional development of EFL teachers

Figure 1 illustrates that $40 \%$ of the respondents considered these courses and workshops as main sources of their continuous professional development. Informal discussions in academic setting were regarded by $17 \%$ of the teachers as means of professional growth. Of all the respondents $15 \%$ perceive educational conference and seminar to be helpful in enhancing classroom pedagogy. Similarly, 13\% teachers considered reading books and articles as professional development tools. However, very few teachers chose mentoring $(10 \%)$ and classroom observation $(5 \%)$ as agents of their professional growth. 


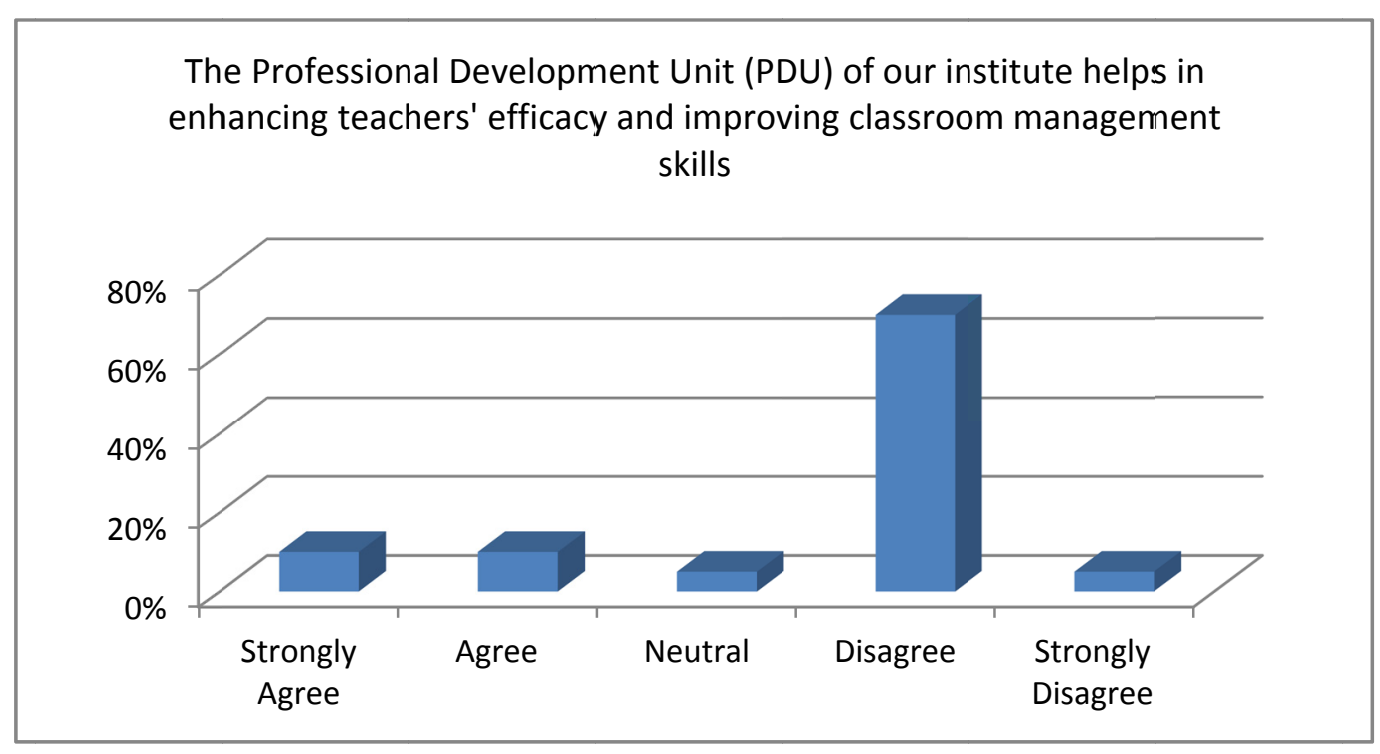

Figure 2. The role of Professional Development Unit

Figure 2 shows that the majority of the respondents disagreed/strongly disagreed with the notion that the Professional Development Unit of the ELI helped the teachers in fulfilling their professional needs. Only $20 \%$ of the respondents put their faith in the endeavors of the PDU.

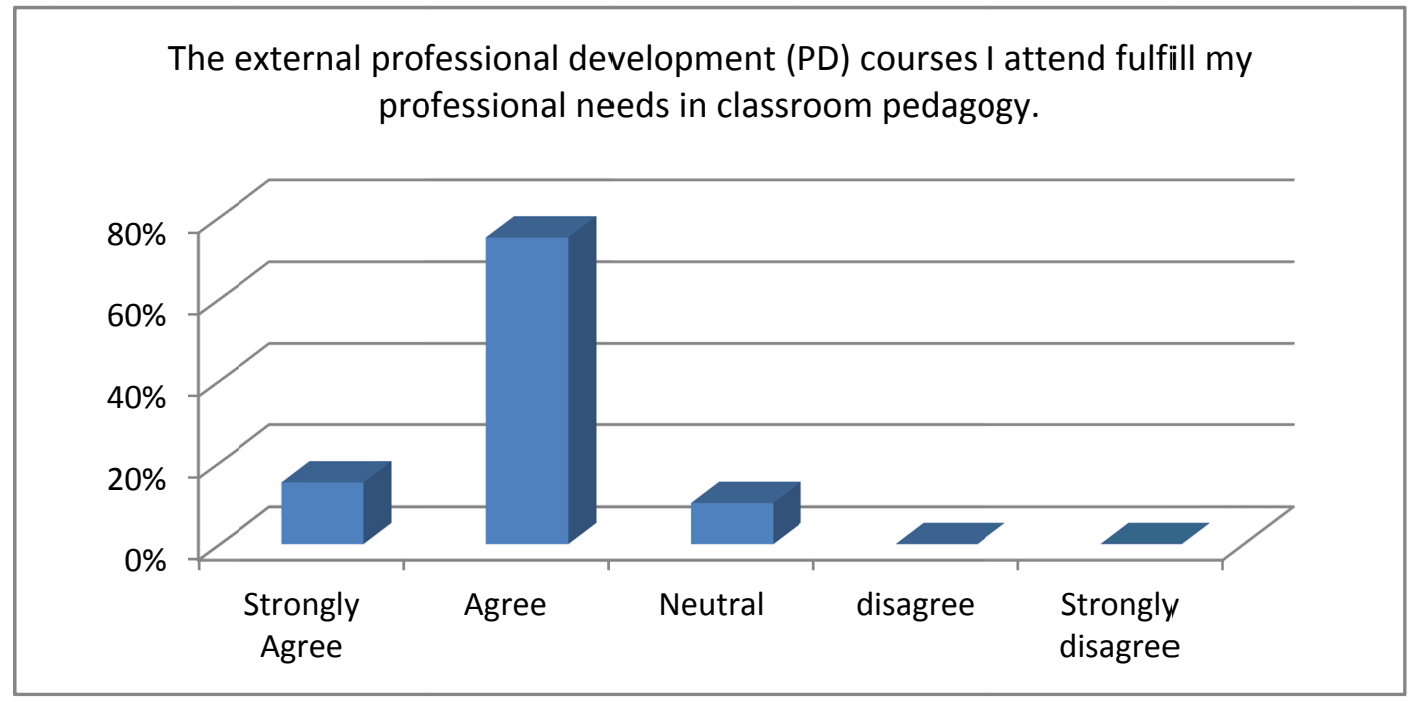

Figure 3. External professional development activities

On the contrary, Figure 3 clearly indicates that almost all instructors (90\%) valued the external professional development courses as these courses fulfill the teachers' needs in classroom pedagogy. Only $10 \%$ of the respondents maintained a neutral position on this point. 


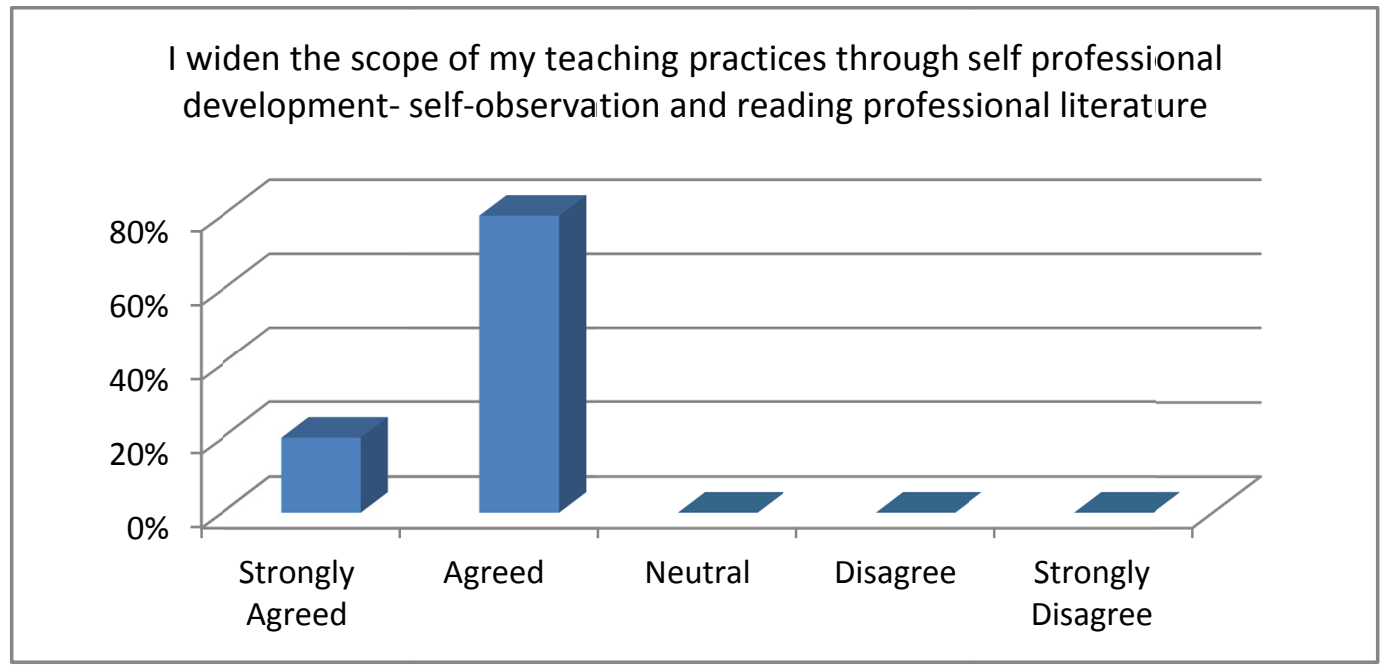

Figure 4. Personal efforts towards professional development

In Figure 4 all teachers had consensus on the usefulness and validity of self-observation and reading professional literature about EFL classroom practices.

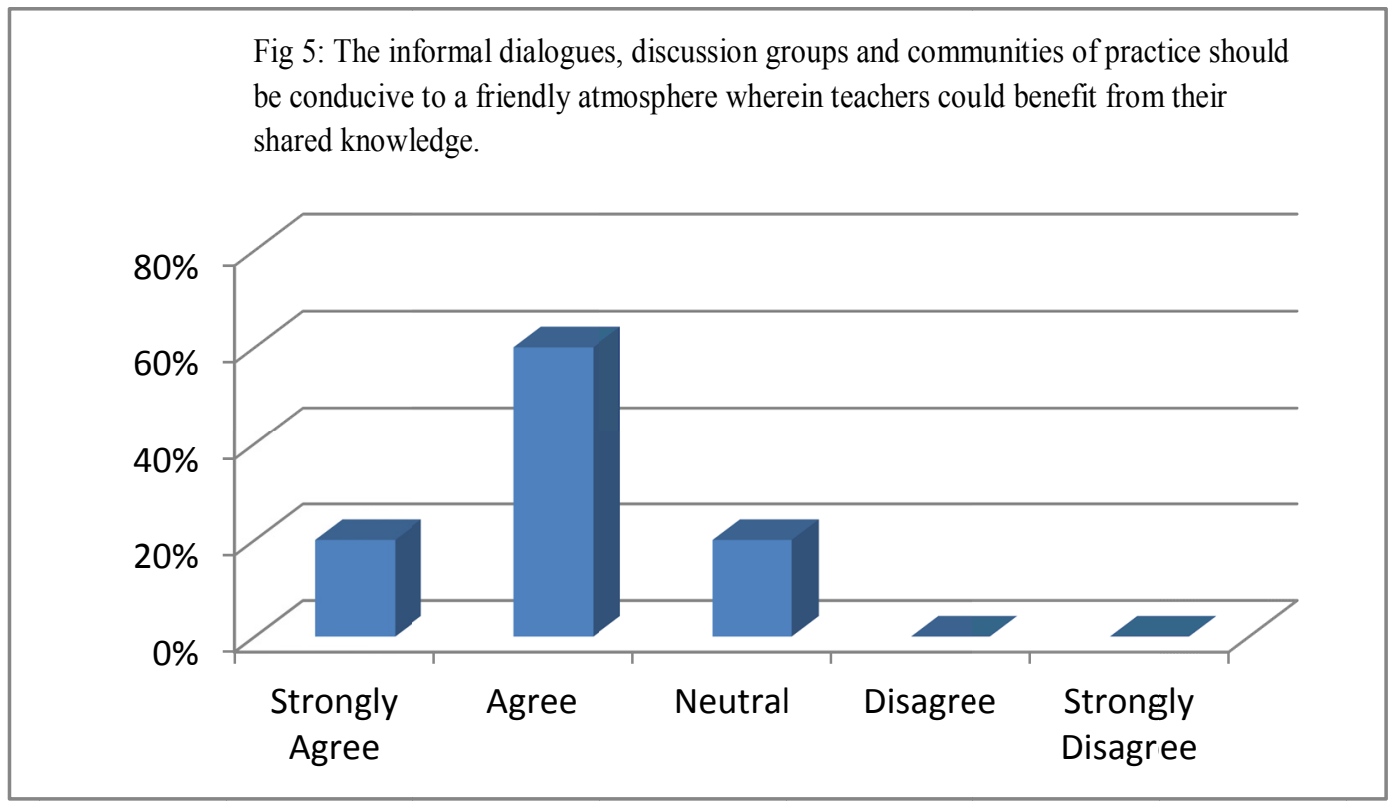

Figure 5. Informal professional development activities

Most of the respondents in Figure $5(80 \%)$ confirmed the cardinal importance of their shared knowledge and expertise via informal dialogues, discussion groups and communities of practices. The informal discussions usually happened at workplaces in educational setting. 


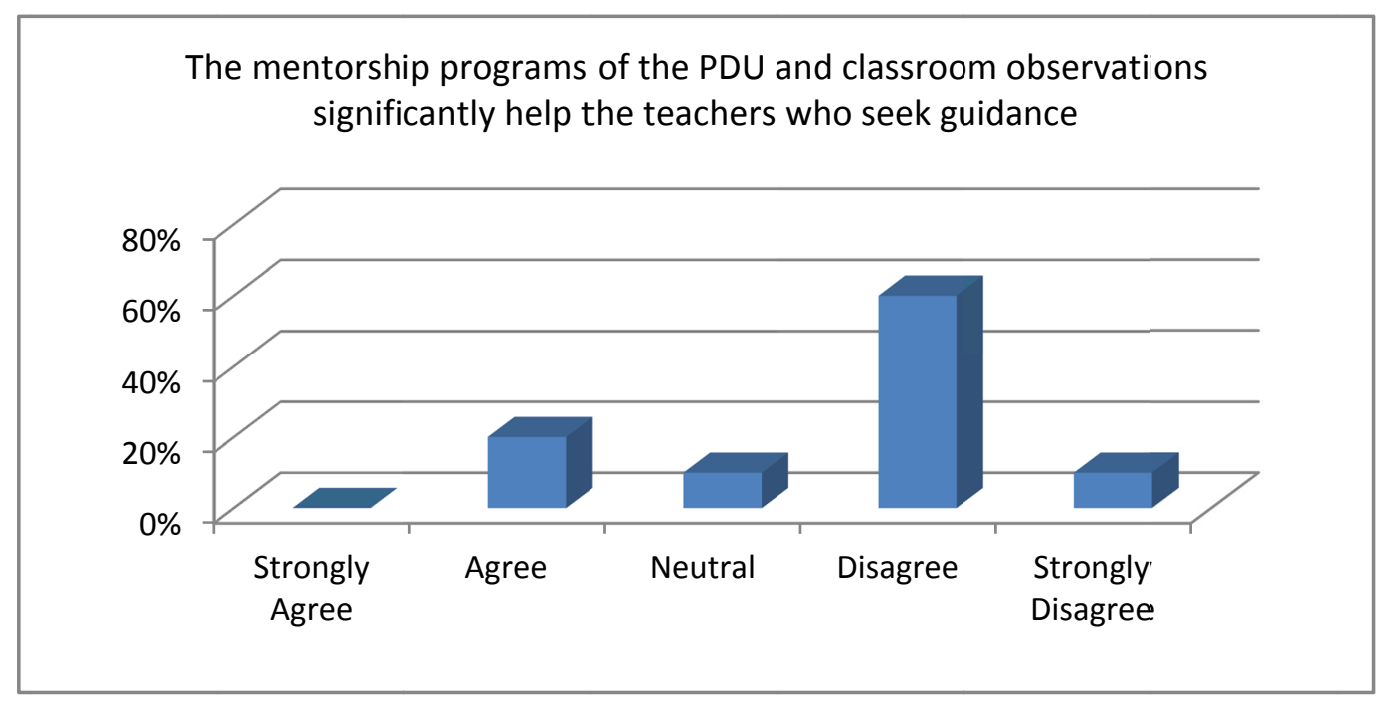

Figure 6. The role of mentorship and classroom observations

Figure 6, interestingly $60 \%$ of the instructors denied the claim that the mentorship program of the PDU and classroom observations significantly enhanced teachers' classroom performance. Whereas only $20 \%$ of the teachers testified the positive role of the above mentioned PD practices.

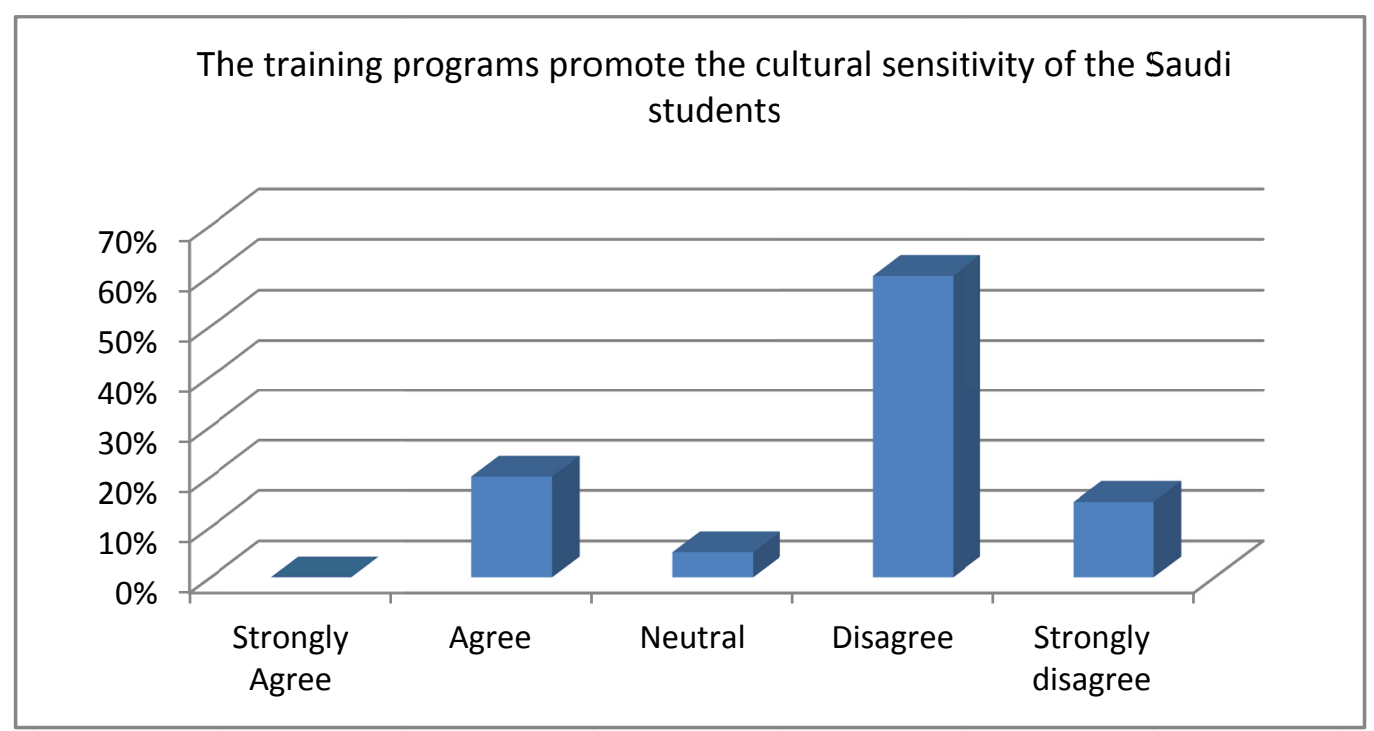

Figure 7. The nature of training workshops

Figure 7 displays $75 \%$ respondents disagreed/strongly disagreed with the statement that the training programs in place could make the teachers aware of the Saudi students' cultural sensitivity. On the other hand, $20 \%$ of the teachers were of the opinion that the PD sessions did inculcate the cultural sensitivity of their students. 
The Traing Programs also promote the cultural sensitivity of the Saudi students

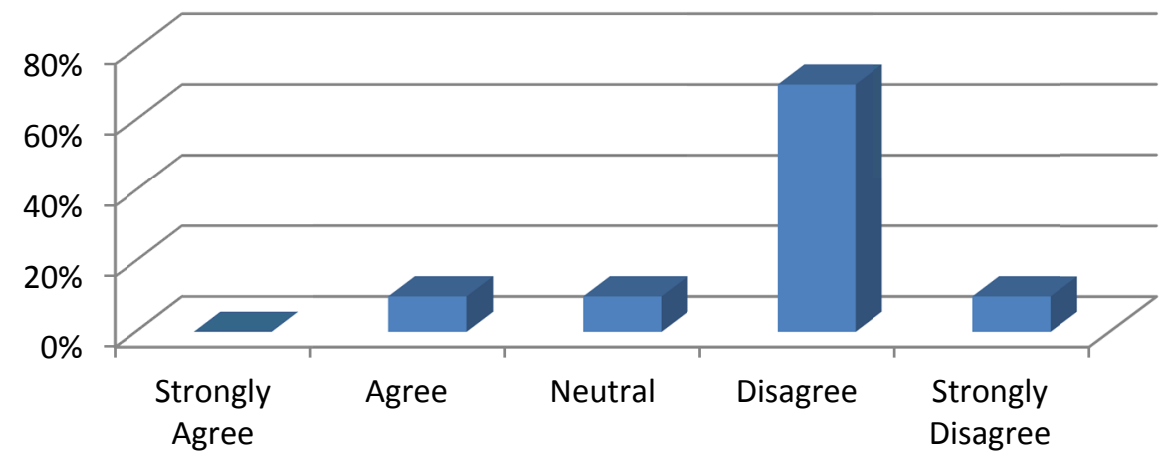

Figure 8. The impact of training workshops

Finally, the respondents $(80 \%)$ showed great disappointment with the lack of cultural awareness factor for teachers in the training programs. Only a meager number of teachers $(10 \%)$ believed that the training programs promoted cultural sensitivity of their students.

\section{Discussion}

The findings of this study illustrates how the EFL teachers at the ELI perceive CPD, what forms of CPD in their teaching context contributed to their professional learning and what factors hindered or helped with their efforts to develop themselves professionally. The following section renders a detail analysis of the teachers' perceptions guided by their years of experience about the existing CPD programs and their expectations from a vibrant and viable CPD program at the ELI.

\subsection{CPD in the Eyes of the EFL Teachers}

For the EFL practitioners in the context of the current research, professional development is life and blood in their bid to shape their beliefs about their teaching abilities. The EFL instructors seem to be aware of the fact that their efficacy is indeed malleable and likely to change but the change should be through engaging and meaningful development opportunities. Overbaugh and $\mathrm{Lu}$ (2008) argue that teachers' efficacy is a desire to implement the changes they believe are efficacious and appropriate. Thus, changes that are introduced by the management without considering teachers' voice may bear no fruit and teachers may not over their weaknesses. Consequently, the teaching and learning outcomes may be affected.

\subsection{The Classroom Observation and Mentoring Program of the PDU}

Classroom observations are integral part of any institution's PD plan for its teachers and meant to improve teachers' practices and students' outcomes embedded within overarching framework of understanding how learning and teaching take place. However, when conducted in a non-systematic way, the classroom observation may backfire and leads to the 
disillusionment of teachers, as Harthi and Shah (2014) observe that instructors perceive the process of observation as perennial pressure owing to their lack of autonomy, observers' subjective approach, observers' lack of training and the overriding element of threat and insecurity. Similarly, in this study respondents showed their lack of satisfaction over the mentoring program in place which does not aid them to improve their performances in classroom, specifically in observed lessons. A mentor can be informed by possessing some overview of what the teaching/learning process is and through such an understanding he can give a powerful insight into the classroom realities which can allow the teachers to put up a good show in an observed lesson and gain confidence as a teacher. According to Goodwyn (1997) it is important for a good mentor to have counseling skills that can help a teacher understand and internalize new emerging classroom practices. So, in the context of this research, teachers show lack of trust both in the mentoring program and classroom observation and they demand that both can be complementary in an ideal setting as mentors can help EFL teachers develop top-notch teaching practices and contribute to their classroom observation.

\subsection{Self-Directed Professional Development Plan}

Most of the respondents in this study prefer self-directed development to institution-based development activities. For teachers self-directed professional development means developing themselves by setting targets to achieve through self-directed learning programs based on their strengths and interests. Self-development for an EFL teacher, according to Richards (2005) is documenting different teaching practices, gauging beliefs and principles, and collaborating with peers on classroom projects. As this study reveals the inadequate number of such programs which forces teachers to rely on the courses offered by the institute, therefore professional development is not up to mark. This also reflects their lack of autonomy and absence of their voice in the institutional policies as pointed by Shah and Al-harthi (2014) which directly impact their classroom performances.

\subsection{External PD Activities}

Although, internal PD programs are deemed ineffective to a great extent, other means could help the teachers to develop their teaching skills. As Richards (2005) mentions critical reflection and self-observation helpful tools in PD of teachers since many things such as mastery of subject matter and pedagogical expertise demand teachers to go beyond personal and individual reflections. Therefore, EFL teachers get involved in external professional development activities such as taking part in conferences and seminars, reading relevant literature, and attending online courses. This reflects the intrinsic motivation of teachers who go beyond the available opportunities and try to explore new areas for their learning.

\subsection{Informal Discussions and Communities of Practice}

Although there is no formal community of practice in this context, the current study highlighted the pressing need for informal discussions and community of practice in educational setting wherein teachers could utilize each other's shared knowledge and beliefs. There is always an urge among teachers for collaborative efforts and self-directed learning. 
Collaborative learning gives rise to collegiality that encourages greater interaction among teachers through forming a community for informal discussions and sharing experiences. According to Richards (2007), in learning communities teachers are provided with opportunities to learn and work together through group-oriented activities.

\subsection{Students' Cultural Sensitivity and CPD}

Knowing target culture knowledge is essential for EFL instructors, especially when the learners have a different cultural background than the instructors. When native English teachers take up teaching EFL in Saudi Arabia, they find it very difficult to cope with cultural differences because they are not sufficiently trained for these. Therefore, in the current study, teachers stressed the importance of cultural knowledge about the EFL learners as the lack of might lead to cultural shock or embarrassment for the teachers. According to Joncour (2013) to properly address the Saudi learners' needs, the EFL instructors and the materials to be accommodating to the Saudi cultural norms and values. Thus, the CPD material should address this phenomenon in the Saudi EFL context as most of the EFL teachers hail from non-Arab countries and often lack cultural awareness of this context.

\section{Conclusion}

Continuing professional development (CPD) is a multi-faceted and continuous experience, which takes place both inside and outside the classroom settings. The present study has attempted to investigate the EFL teachers' perceptions and beliefs about the CPD in their teaching context. EFL teachers in Saudi Arabia are engaged in professional development programs which have measurable impacts on their classroom performances as well as their learners' achievement. This investigation brought forth the fact that teachers see greater development opportunities in external programs such as courses, seminars, workshops and conferences, and self-directed endeavors like informal discussions, reading professional literature, and self-reflection. However, teachers are disappointed with the institution-based professional programs which have little impact on their teaching. The classroom observations conducted by the PDU are questioned due to the lack of reliability, objectivity, validity and consequences hereafter. Additionally, the mentoring system in place is not consistent with the diverse challenges faced by instructors and consequently teachers rarely approach mentors for guidance. Thus the institution's role in the continuous professional development of the teachers is limited to few stereotypical activities which are not conducive to dynamic growth of teachers in the professional arena. Therefore, it is recommended that the institution allows the PDU to adopt promising approaches for evaluating the staff. In addition, based on the findings of the study, it is recommended that the institution should revamp its internal professional development scheme and expand the PDU role beyond teacher performance appraisal. Well-intentioned observers should be available to filter out their bias against a specific methodology or personality while observing a classroom. Furthermore, qualified mentors should be inducted who know the challenges faced by the teachers and are well-qualified in the subject. In addition to the overhauling of the PDU, learning communities should be set up where teachers have the chance to engage in professional dialogue and collaborative inquiries that encourage continuous growth and development. In addition, 
faculty, especially the newly arrived teachers should be offered opportunities to develop some understanding of the Saudi culture and customs, as awareness of the learners' culture immensely impacts students' learning outcomes.

\section{References}

Adey, P. (2004). The Professional Development of Teachers: Practice and Theory. Kluwer Academic Publishers Dordrecht.

Al-Haisoni, E. \& Rahman, M.M. (2013). Teaching English in Saudi Arabia: Prospects and Challenges. Academic Research International, 4(1), 112-118.

Al-Harbi, A. (2006). Training Needs of English Teachers in Al-Qassim Province. Unpublished master's thesis, King Saud University, Riyadh, Saudi Arabia.

Al-Hazmi, S. (2003). EFL teacher preparation program in Saudi Arabia: Trend and challenges. TESOL Quarterly, 37(2), 341-344. http://dx.doi.org/10.2307/3588509

Al-Seghayer, K. (2005). Teaching English in Saudi Arabia: Slowly but steadily Changing. In G. Braine (Ed.), Teaching English to the world (pp. 115-130). Mahwah, NJ: Lawrence Erlbaum Association.

Al-Seghayer, K. (2014). The Actuality, Inefficiency, and Needs of EFL Teacher-Preparation Programs in Saudi Arabia. International Journal of Applied Linguistics \& English Literature, $3(1), 141-151$.

Alshuaifan, A. (2009). Key elements of ESL/EFL teacher preparation program at the University of Ha'l, Saudi Arabia: EFL practitioners and faculty perceptions. Unpublished doctoral dissertation. West Virginia University,Morgantown.

Alsofi, A. A. (2009). Designing a Refresh Course for In-Service Teachers of English in Yemen, Unpublished M. A. Thesis, Faculty of Education, Hodeidah University.

Byram, M. (2005). Foreign Language Teachers and Intercultural Competence. Multilingual Matters Limited.

Cohen, L., Manion, L., \& Morrison, K. (2007). Research Methods in Education (6th Edition). London: Routledge Falmer.

Fullan, M. (2001). Leading in a Culture of Change. San Francisco: Jossey-Bass.

Fullan, M. G., \& Stiegelbauer, S. (1991). The New Meaning of Educational Change.

Glatthorn, A. (1995). Teacher Development. In Anderson, L. (2nd Ed.), International Encyclopedia of Teaching and Teachers Education. London: Pergamon Press.

Goodwyn, A. (1997). Developing English Teachers. Open University Press Buckingham.

Heyes, D. (2014). Innovations in the Continuous Professional Development of English Language Teachers. British Council London. 
Joncour, C. L. (2013). ELT in the Middle-East: curricula and teacher competencies under the intercultural scrutiny. English Language and Translation conference Making Connection Towards a Successful Future.

Khan, I. A. (2011). The Teacher of English: Pedagogic Relevance in Saudi Arabia. English Language Teaching, 4(2), 112-120.

Krosnick, J. A., \& Presser, S. (2010). Question and Questionnaire Design. Handbook of Survey Research (2nd ed., pp. 263-313).

Liebscher, P. (1998). Quantity with Quality? Teaching Quantitative and Qualitative Methods in an LIS Master's Program. Liberty Trends, 46(4), 668-680.

Lodico, M. G., Spaulding, D. T., \& Voegtle, K. H. (2010). Methods in Edwcational Research: From Theory to Practice. Jossey-Bass, San Francisco.

Lu, R., \& Overbaugh, R. (2008). The effects of NCLB-funded instructional technology training on teachers' classroom practice. VSTE Journal, 22(3), 1-15.

Magno, C. (2009). Developing Contemporary Teaching Perspectives for EFL Teachers, De La Salle University, Manila, Philippines ESL Journal, Vol. 2, February.

Mcdonald, C. (2010). A Pre-Trial Collection And Investigation of What Perceptions And Attitudes of Konglish Exist Amongst Foreign And Korean English Language Teachers In Terms of English Education in Korea, Canada-Vietnam Foreign Language Centre. The Asian EFL Journal, 12(1), 134-164.

Open University Team. (2001). Research Methods in Education.

Prosser, M., \& Trigwell, K. (1999). Understanding learning and teaching: the experience in higher education, Buckingham, Open University Press.

Raza, N. A. (2010). The impact of continuing professional development on EFL teachers employed in federal universities in the United Arab Emirates. Phd Thesis, University of Exeter.

Richards, J. C., \& Farrell, T. S. C. (2005). Professional development for language teachers. New York, NY: Cambridge University Press. http://dx.doi.org/10.1017/CBO9780511667237

Shah, S. R., \& Al Harthi, K. (2014). TESOL classroom observations: a boon or a bane? An exploratory study at a Saudi Arabian university. Theory and Practice in Language Studies, 4(8), 1593. http://dx.doi.org/10.4304/tpls.4.8.1593-1602

Shah, S. R., Hussain, M. A., \& Nasseef, O. A. (2013). Factors Impacting EFL Teaching: An Exploratory Study in the Saudi Arabian Context. Arab World English Journal.

Trochim, W. (2006) Likert Scaling. Retrieved from http://www.socialresearchmethods.net/kb/scallik.php

Villegas-Reimers, E. (2003). 'The Professional Development: An International Review of Literature' International Institute for Educational Planning. Paris. 


\section{Macrothink}

Zafer, A. (2002). A Survey of Saudi School Teachers' and College Professors' Perspectives on topics and Roles to Emphasize in English as a Foreign Language in Teacher Preparation Course. Unpublished doctoral dissertation. University of Kansas, Lawrence, Kansas.

Zohairy, S. (2012). Professional development challenges and possible solutions. In Al-Amri, W., Noor, H., and McGee,I. (Eds.). Saudi Preparatory Year English Program: The Future and Beyond: student, teacher, pedagogy and curricular issues (pp. 162-183). Madinah, Taibah University.

Zuheer, K. M. M. (2013). Developing EFL Teachers' Performance at Sana'a Secondary Schools in the Light of their Professional and Specialist Needs. PhD thesis, Cairo University.

\section{Copyright Disclaimer}

Copyright reserved by the authors.

This article is an open-access article distributed under the terms and conditions of the Creative Commons Attribution license (http://creativecommons.org/licenses/by/3.0/). 